\title{
DIREITO À MORADIA E GENTRIFICAÇÃO: A POLÍTICA DE ALUGUEL EM FOCO
}

\section{RIGHT TO HOUSING AND GENTRIFICATION: THE RENT POLITICS IN FOCUS}

\author{
${ }^{1}$ Leandro Teodoro Andrade \\ ${ }^{2}$ Zulaiê Loncarcci Breviglieri
}

\begin{abstract}
RESUMO
O presente estudo aborda as formas de realização do Direito Fundamental Social à Moradia e as respectivas políticas públicas de Habitação no Brasil. Analisa como se dá a produção do espaço urbano no país, partindo desde os paradigmas advindos com o extinto Banco Nacional de Habitação (BNH) até os dias atuais. Trabalha a definição daquilo que é efetivamente o direito à moradia, com enfoque na tradição patrimonialista brasileira. Perpassa pelas consequências da má administração da política habitacional em nível nacional e, assim, formula perspectivas para possíveis soluções ao grande déficit habitacional e à segregação urbana em nossas cidades.
\end{abstract}

Palavras-chave: Direito à moradia, Gentrificação, Aluguel subsidiado

\begin{abstract}
This study addresses the embodiments of the Social Fundamental Right to Housing and there lated public policies of housing in Brazil. It analysis how is the production of urban space in Brazil, starting from the paradigms arising with the former National Housing Bank (BNH) until nowadays. It works the definition of what is effectively the right to housing, with a focus on patrimonial tradition of the exercise of housing in Brazil. Intersects them is management consequences of housing policy at the national level and through this formula prospects for possible solutions to the large housing deficit in our cities.
\end{abstract}

Keywords: Right to housing, Gentrification, Subsidized rent

\footnotetext{
${ }^{1}$ Mestrando em Direito pela Universidade Estadual Paulista Júlio de Mesquita Filho - UNESP, São Paulo (Brasil). E-mail: leandroteodoroa@gmail.com

${ }^{2}$ Mestranda em Direito pela Universidade Estadual Paulista Júlio de Mesquita Filho - UNESP, São Paulo (Brasil). E-mail: zubreviglieri@gmail.com
} 


\section{INTRODUÇÃO}

A falta de moradia é um problema social brasileiro perceptível que chama a atenção. Quando vislumbramos a realidade de nossas metrópoles, fica claro o grande número de habitações sem a mínima infraestrutura física, geográfica e até sanitária, dentre outras deficiências. Essa realidade contrasta com a previsão constitucional que afirma ser a moradia um direito fundamental social previsto no caput do art. $6^{\circ}$ de nossa Constituição Federal.

Sendo a moradia assim definida, a responsabilidade do Poder Público quanto a sua efetivação o obriga a efetivar políticas que possibilitem um amplo acesso à adequada realização da Moradia na produção social do espaço urbano. Todavia, o que ocorre na prática cotidiana das cidades brasileiras é a concepção da moradia enquanto produto. A realização deste direito social se encontra à mercê das intempéries de nossa formatação socioeconômico, assumindo a natureza muito mais de um bem de consumo do que um direito social basilar à dignidade da pessoa humana de qualquer cidadão.

Neste sentido, o estudo pretende: analisar as contradições socioeconômicas e as políticas públicas adotadas no Brasil; analisar a correlação entre produção social do espaço, a atual formatação socioeconômica brasileira, o mercado imobiliário e as políticas públicas habitacionais nacionais desde o Banco Nacional de Habitação, até o Programa Minha Casa Minha Vida; verificar o fenômeno da "gentrificação", sua correlação com o mercado imobiliário e suas consequências sociais; buscar perspectivas que norteiem soluções ao déficit habitacional e à segregação urbana, como as políticas de aluguel subsidiado, que têm sido utilizadas em muitos países.

No campo da metodologia, utiliza-se uma abordagem bibliográfica transdisciplinar, abrangendo tanto a literatura nacional quanto estrangeira. Serão utilizados, ainda, dados empíricos provenientes de estatísticas, índices e estudos aplicados para tratar do tema com maior clareza e aprofundamento.

\section{MAIS MORADIAS, MAIS DÉFICIT HABITACIONAL: MERCADO E ESTADO NO BRASIL}

Com a extinção dos Bancos Nacionais de Habitação (BNHs), em 1986, o Brasil viveu uma lacuna de políticas públicas de moradia que perdurou até o ano de 2009, com o lançamento do Programa Minha Casa Minha Vida (PMCMV). Após o hiato de vinte e 
três anos, o programa que até o ano de 2015 contratou quase 4 milhões de moradias ${ }^{1}$ surgiu como uma alternativa anticíclica para a crise mundial de 2008, que, ironicamente, teve início com a explosão da bolha imobiliária nos Estados Unidos, tendo sido a pior crise já enfrentada por aquele setor na história norte-americana.

Ainda que o PMCMV tenha emergido mais como política econômica do que propriamente uma política habitacional, os números do programa impressionam por sua expressividade. Considerando, assim, a complexidade dessa política pública de grande impacto socioeconômico, faz-se necessária uma avaliação mais criteriosa do programa governamental para que seja auferida a eficácia real das medidas adotadas, implicando no planejamento dos investimentos públicos e sua efetividade para a melhora dos indicadores que revelam a qualidade de vida do cidadão.

O índice de déficit habitacional quantitativo é um dado de extrema relevância para essa avaliação, podendo indicar de forma mais clara e objetiva o alcance das medidas públicas adotadas. Neste liame, recente pesquisa realizada pela Fundação João Pinheiro, instituto mineiro que estuda o tema em parceria com o Ministério das Cidades, revela que, mesmo com a grande produção de habitações encampada pelo governo federal, o déficit habitacional cresceu 10\% entre 2011 e 2012 nas nove metrópoles monitoradas pelo Instituto Brasileiro de Geografia e Estatística ${ }^{2}$. O estudo revela que 5,8 milhões de famílias brasileiras carecem de habitação adequada, e que com o valor do aluguel cada vez mais caro, o direito fundamental à moradia sido dificultado, sobretudo nas grandes cidades. Em São Paulo o déficit habitacional atingiu o percentual de 18,2\% em apenas um ano, e alcançou a marca de 700 mil famílias residindo em moradias consideradas inadequadas.

A Fundação João Pinheiro utilizou-se de quatro categorias para classificar as moradias precárias:1) habitações precárias, como locais sem saneamento ou que apresentam riscos; 2) coabitação familiar, ou seja, quando mais de uma família divide a mesma residência por falta de opção; 3) ônus excessivo com aluguel urbano, que ocorre quando mais de $30 \%$ da renda de famílias pobres são comprometidas com o aluguel; 4) adensamento excessivo em domicilios alugados, que é registrado quando, em média, mais de três pessoas compartilham um mesmo dormitório na casa. Quanto ao item 3, o

\footnotetext{
1 Informação disponível em: http://www.bras il.gov.br/infraes trutura/2016/03/em-s ete-anos -minha-cas aminha-vida-entrega-mais -de-1-000-cas as-por-dia. Acesso em: 13/03/2016.

2 FUNDAÇÃO JOÃO PINHEIRO. Déficit Habitacional no Brasil / 2011-2012. Governo de Minas Gerais, Belo Horizonte, 2015. Disponível em: http://www.fjp.mg.gov.br/index.php/docman/cei/559deficit-habitacional-2011-2012/file. Acesso em: 15/03/2016
} 
Instituto considera apenas as familias com renda total de até três salários mínimos para a análise de gasto excessivo com moradia, tendo constatado que mais de $30 \%$ da renda mensal das famílias inseridas nessa faixa é utilizada para o pagamento de aluguel, ocupando uma fatia bastante onerosa da renda familiar mensal, comprometendo o custeio de outros gastos essenciais com alimentação, transporte e saúde.

A constatação da Fundação João Pinheiro se reafirma pelo que aponta o índice Fipe-Zap ${ }^{3}$. O indicador revela que, entre os anos de 2008 a 2014, o valor médio do aluguel teve alta $97 \%$ na cidade de São Paulo, e de $144 \%$ na cidade do Rio de Janeiro, tendo crescido mais do que a renda da população, refletindo o aquecimento das leis de mercado que regem o setor imobiliário e a valorização dos terrenos em decorrência de eventos como a Copa do Mundo de 2014, ou mesmo a produção habitacional pelo Minha Casa Minha Vida, que valoriza áreas da periferia das cidades, impulsionando ainda mais a alta dos preços nos centros urbanos ${ }^{4}$.

O que não se pode perder de vista é o fato de que, antes de tudo, a cidade é um espaço de disputas. Nesse cabo de guerra há diversos fatores em jogo, dentre eles as leis de mercado e força normativa exercida pelo Estado, que tenta intervir em favor ora dos direitos fundamentais ora em fomento aos próprios atores privados e à economia, interferindo assim no espaço urbano e sua configuração socioeconômica. É o que aponta Castells (1982):

[...] o Estado não é um agente neutro; nem tampouco o instrumento de uma minoria oligárquica como certas visões esquemáticas, às vezes, tratam de assinalar. A intervenção do Estado é uma intervenção complexa, determinada no plano do urbanismo, em primeiro lugar, pelos conflitos políticos e sociais subjacentes à ação pública, quer dizer, pelo enfrentamento no seio do Estado e com relação ao Estado de grupos sociais e de grupos de interesse ${ }^{5}$.

Ocorre que, quando o assunto é moradia, o mercado imobiliário e a especulação, não raramente, acabam levando vantagem em detrimento da necessidade dos que mais precisam.

\section{O DIREITO À MORADIA E A PRODUÇÃO DO ESPAÇO URBANO}

$\mathrm{O}$ direito à moradia, previsto no rol de direitos fundamentais sociais do art. $6^{\circ}$ da Constituição Federal brasileira, desde a Emenda Constitucional $n^{\circ} 26 / 2000$, tem em

\footnotetext{
${ }^{3}$ Disponível no endereço eletrônico: http://www.zap.com.br/imoveis /fipe-zap-b/. Acesso em: 15/03/2016.

${ }^{4}$ Informações disponíveis no endereço eletrônico:

http://www.bbc.com/portugues e/noticias/2014/05/140527_deficit_habitacional_ms. Acessoem: 16/03/2016.

5 CASTELLS, Manuel. A intervenção adminis trativa nos grandes centros urbanos . Espaço e Debates. São Paulo, n. 6.1982, p. 69.
} 
sua efetivação uma importância nuclear para a realização de demais direitos fundamentais sociais - tais como saúde, educação e lazer. É pressuposto para o respeito à dignidade da pessoa humana, fundamento de nossa República e, conforme aponta

Soraya Lunardi:

Uma abordagem sistemática dos direitos fundamentais sociais é necessária para demonstrar que a omissão estatal do direito à moradia, além de privar o titular da prestação constitucionalmente imposta, afeta de maneira direta ou indireta uma série de outros direitos fundamentais ${ }^{6}$.

Ter para si e sua família uma moradia adequada, com possibilidade de acesso aos bens estruturantes da Cidade, é o requisito básico para que cada ser humano produza sua singularidade histórica no mundo e, assim, torne-se, efetivamente, um cidadão. É por conta desta centralidade própria que o direito à moradia possui um conteúdo jurídico complexo, trazendo em seu bojo uma série de requisitos para que sua efetivação produza realmente efeitos concretos para além dos aspectos meramente quantitativos de índices de avaliação de políticas públicas.

Neste sentido, o Comitê de Direitos Econômicos, Sociais e Culturais da Organização das Nações Unidas emitiu seu Comentário Geral no 04 sobre o Pacto Internacional de Direitos Econômicos Sociais e Culturais (ratificado pelo Brasil em 1992), definindo como moradia adequada aquela que contemplasse os seguintes critérios:

I. Segurança da posse: a moradia não é adequada se os seus ocupantes não têm um grau de segurança de posse que garanta a proteção legal contra despejos forçados, perseguição e outras ameaças.

II. Disponibilidade de serviços, materiais, instalações $e$ infraestrutura: a moradia não é adequada, se os seus ocupantes não têm água potável, saneamento básico, energia para cozinhar, aquecimento, iluminação, armazenamento de alimentos ou coleta de lixo.

III. Economicidade: a moradia não é adequada, se o seu custo ameaça ou compromete o exercício de outros direitos humanos dos ocupantes.

IV. Habitabilidade: a moradia não é adequada se não garantir a segurança física e estrutural proporcionando um espaço

\footnotetext{
${ }^{6}$ LUNARDI, Soraya Regina Gasparetto. Finalidades e Formas de efetivação do Direito Fundamental à Habitação: a inclusão social com base na experiência constitucional francesa. In. LUNARDI, Soraya Regina Gasparetto (Org). Inclusão Social e sua Efetivação. Curitiba: CRV, 2011. P. 177
} 
adequado, bem como proteção contra o frio, umidade, calor, chuva, vento, outras ameaças à saúde.

V. Acessibilidade: a moradia não é adequada se as necessidades específicas dos grupos desfavorecidos e marginalizados não são levados em conta.

VI. Localização: a moradia não é adequada se for isolada de oportunidades de emprego, serviços de saúde, escolas, creches e outras instalações sociais ou, se localizados em áreas poluídas ou perigosas.

VII. Adequação cultural: a moradia não é adequada se não respeitar e levar em conta a expressão da identidade cultural ${ }^{7}$.

Com base nesses elementos podemos afirmar que a Moradia, como direito fundamental social, constitucionalmente tutelado, não pode ser reduzido a um produto qualquer que se encontra nas prateleiras do mercado especulativo. Todavia, a organização socioeconômica e as formas de sociabilidade contemporânea atrelam a (re)produção do espaço urbano a uma lógica pautada pelos interesses de mercado, gerando desagregações e segregações típicas do capitalismo, uma vez que os recursos que formam a estrutura das cidades, necessários ao mínimo de cidadania à vida dos citadinos são, em boa parte das vezes, restritos a apenas uma parcela da população que não está relegada às zonas periféricas longínquas de habitação, como ainda tem acontecido frequentemente com os extratos mais baixos de nossa sociedade. É o que enfatiza Arlete Moyses Rodrigues:

Somente os que desfrutam de determinada renda ou salário, podem morar em áreas bem servidas de equipamentos coletivos, em casas com certo grau de conforto. Os que não podem pagar, vivem em arremedos das cidades, nas extensas e sujas ,periferias" ou nas áreas centrais ditas „deterioradas ${ }^{\text {ee }}$. Nestes arremedos de cidades, há inclusive aqueles que „não moram"e, vivem embaixo de pontes, viadutos, em praças, em albergues, não tem um teto fixo ou fixado no solo. Nestes arremedos de cidade, de sujeira, o que torna cada dia mais difícil de ter força para resistir a esta cidade e aos efeitos da miséria. $^{8}$

Assim, a distribuição de moradias nas cidades assumem contornos hierarquicamente delimitados. Qualificam-se conjuntos habitacionais e glebas territoriais de uma mesma cidade conforme o estrato social mais apto para ali se estabelecer. Hodiernamente, o espaço assume assim o seu valor de uso e troca, traduzido em valorização e desvalorização pecuniária, ao passo que o direito à moradia

\footnotetext{
7 BRASIL, Secretaria de Direitos Humanos da Presidência da República. Direito à Moradia Adequada. Brasília: Secretaria Nacional de Direitos Humanos, 2013. P. 13.

${ }^{8}$ RODRIGUES, Arlete Moysés. Moradia nas Cidades Brasileiras. 2ed. São Paulo: Contexto, 1989. p. 12.
} 
transforma-se em um bem intangível a boa parte da população por confundir-se, ainda, na relação de propriedade tutelada pelos institutos de direito civil.

Ana Fani Alessandri Carlos, por sua vez, assevera que:

A produção do espaço como mercadoria efetua-se em dois níveis: através da produção da habitação, uma mercadoria intercambiável no mercado imobiliário, sem o qual a função da moradia não se realiza; e através da produção da própria cidade pelo trabalho social presente e acumulado ao longo da história. Para o capital, a materialidade do espaço é o suporte do valor de troca, a forma como a natureza, pela extensão do processo de urbanização, criou o espaço como produto imobiliário e como rede de infraestrutura, articulando o público e o privado numa morfologia diferenciada socialmente. Para a vida ${ }^{9}$.

Muitas vezes essa lógica de exclusão e segregação é promovida pelo próprio Poder Público, seja por conta de políticas habitacionais que criam conjuntos populares para financiamento de casa própria em áreas urbanas longínquas, longe da infraestrutura necessária a que a moradia seja adequada, tanto geográfica tanto estruturalmente, seja pelas condições precárias de acesso e permanência espacial, seja pela distância dos bens vitais disponibilizados pela cidade - tais como emprego, saúde, educação e lazer institucionalizando a segregação social do espaço ${ }^{10}$. Ou ainda criando programas de valorização imobiliária de determinadas áreas que, por sua vez, gera uma expulsão dos moradores originários a áreas mais precárias da cidade ${ }^{11}$.

É exatamente por conta destes fatores que um programa habitacional que vise reverter o problema do déficit por moradia adequada no Brasil ${ }^{12}$, equacionando as necessidades habitacionais nacionais num período razoável, não deve seguir a lógica especulativa sob a qual desde muito vem sendo construída a produção do espaço urbano, mas conceber a moradia enquanto um direito fundamental social indispensável ao respeito da dignidade da pessoa humana e à efetivação de demais direitos fundamentais sociais.

\footnotetext{
${ }^{9}$ CARLOS, Ana Fani Alessandri. A Tragédia Urbana. In. CARLOS, Ana Fani Alessandri; VOLOCHKO, Danilo; ALVAREZ, Isabel Pinto (orgs.). A Cidade Como Negócio. São Paulo: Contexto, 2015. p. 50.

10 Um grande exemplo é a atuação do Programa Minha Casa Minha Vida (PMCMV) na região metropolitana de Natal, como bem abordado em: MOURA, Jéssica Morais de. O Programa Minha Casa, Minha Vida na Região Metropolitana de Natal: uma análise espacial dos padrões de segregação e desterritorialização. urbe, Rev. Bras. Gest. Urbana, Curitiba , v. 6, n. 3, p. 339359, Dec. 2014 . Dis ponível em: http://www.s cielo.br/s cielo.php?s cript=sci_arttext\&pid=S2175$33692014000300006 \& \operatorname{lng}=$ en \&nrm=iso. Aces so em 20/03/2016.

${ }^{11}$ A exemplo disso, o projeto Nova Luz, que vislumbrava a revitalização de determinada área central da cidade de São Paulo. Para tanto: http://noticias .r7.com/s ao-paulo/jus tica-determina-quenbs pprojetonova-luz-s eja-refeito-24012013. Aces so em 20 de Março de 2016.

12 Objetivo primordial do Plano Nacional de Habitação de 2009.
} 


\section{POLÍTICA DE HABITAÇÃO OU POLÍTICA ECONÔMICA? O HISTÓRICO BRASILEIRO E A CULTURA PATRIMONIALISTA}

A respeito do acima exposto, certo é que, em nível federal, o Brasil nunca viveu uma política de habitação desvinculada de uma lógica que obedecesse aos ditames mercadológicos. Desde a época da Primeira República, quando o projeto modernizador do Rio de Janeiro imposto pelo governo de Rodrigues Alves expulsou a população pobre da então capital federal aos morros e áreas longínquas da cidade (originando o fenômeno urbano que hoje conhecemos como favelização) até os dias atuais, em que a despeito da previsão constitucional da moradia enquanto direito fundamental social e de todo o arcabouço jurídico disponível, as políticas públicas de habitação ainda são erigidas sob a lógica do mercado especulativo.

O próprio Banco Nacional de habitação $(\mathrm{BNH})$, instituído no dia 27 de agosto de 1964, período em que a Ditadura Militar brasileira vinha delineando seus contornos e diretrizes políticas - apesar de sua criação ter sido a primeira manifestação de intervenção estatal em grandes níveis na área de habitação - mostrou-se, em seu desenvolvimento, mais um projeto de natureza econômica do que um suporte para financiamento de programas de habitação ${ }^{13}$. O surgimento do Banco Nacional de Habitação, também acompanhou um período de intensa transição da população do campo para as cidades, que criou no imaginário popular brasileiro uma nova cultura de relação com o urbano.

\section{Brasil - Evolução da População 1940 - 2000}

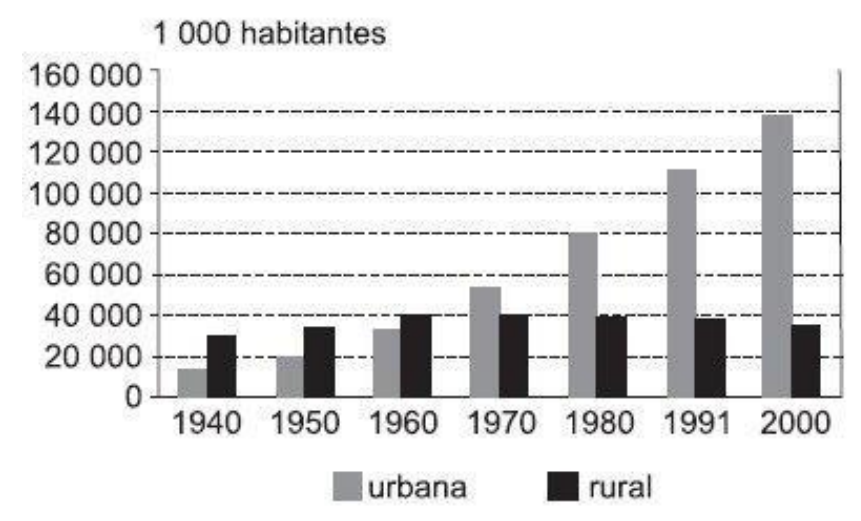

FONTE: Censo Demográfico 2000. Instituto Brasileiro de Geografia e Estatística (IBGE)

13 MEDEIROS, Sara Raquel Fernandes de. BNH: outras perspectivas. P. 03. Disponível em: http://www.cchla.ufrn.br/cnpp/pgs /anais/Artigos \%20REVISADOS/BNH,\%20outra\%20pes pectiva.pdf Acesso 21.02.2016. 
A forma produtivista e a cultura de propriedade que a utilização econômica da terra consolidou historicamente no Brasil, bem como a esperança por "dias melhores" do trabalhador que migrava do campo para a cidade, gerou no imaginário coletivo brasileiro o famigerado sonho da casa própria. Além disso, a casa própria, devido também à própria relação de produção privada do espaço, assumia para as famílias brasileiras uma certa segurança patrimonial, o que contribuía também para que cada vez mais a relação de moradia e propriedade ficassem entrelaçadas.

Diante de uma crescente instabilidade política e econômica em que o governo militar brasileiro se encontrava, a proliferação do sonho da casa própria alicerceado pelo aumento da demanda do rentável setor da construção civil foi aquilo que a organização burocrática estatal precisou para transformar política habitacional em estratégia de política econômica, uma vez que assim era possível um enlace entre as perspectivas políticas e econômicas do governo com os anseios sociais.

Assim, o BNH se mostrou enquanto um eficaz instrumento para potencializar a economia, uma vez que o setor da construção civil consumia cada vez mais mão de obra, enquanto o crescente setor imobiliário movimentava o capital do sonho da casa própria, e ainda, para auxiliar o lado empresarial do $\mathrm{BNH}$, foi criado o Sistema Financeiro Habitacional (SFH), que captava recursos advindos do FGTS (Fundo de Garantia por Tempo de Serviço) e do SBPE (Sistema Brasileiro de Poupança e Empréstimo), com base no sistema de poupança voluntária ${ }^{14}$, sendo o FGTS utilizado para financiar os estratos da classe baixa e o SBPE para os estratos da classe média. Neste sentido, o BNH e seu componente empresarial, o SFH, já deslocavam a questão da habitação do social para o financeiro. O habitar já, desde então, não é um componente básico para a dignidade da pessoa humana do cidadão, mas uma estratégia política de engendramento econômico-financeiro.

Este modelo enraizou a ideia do enlace moradia/propriedade, favorecendo ainda mais noção de moradia, não enquanto um direito, mas enquanto uma mercadoria. O grande problema desta situação é que a moradia enquanto mercadoria assume um custo altíssimo. Trabalhadores, trabalhadoras e famílias, muitas vezes se endividam por toda a vida, comprometendo outras necessidades básicas vitais (como saúde, alimentação, vestuário, lazer e outras) por conta do sonho da casa própria, comprometendo drasticamente a qualidade de vida de milhares de pessoas das classes

${ }^{14}$ Idem. P. 05. 
média e baixa da sociedade brasileira. Para Ermínia Maricato, a habitação, exatamente por conta de seu custo absolutamente antagônico à realidade salarial do trabalhador brasileiro, torna-se uma espécie de mercadoria especial, segundo seus próprios dizeres:

A habitação é uma mercadoria especial, que tem produção e
distribuição complexas. Entre as mercadorias de consumo privado
(roupas, sapatos, alimentos, etc.) ela é a mais cara. Seu preço é muito
maior do que os salários médios, e por isso o comprador demora
muitos anos para pagá-la ou para juntar o valor que corresponde ao
seu preço. Dizemos que é uma mercadoria que tem longo período de
circulação e por isso exige um financiamento prévio para o consumo,
pois em geral os trabalhadores não possuem tanto dinheiro à vista ${ }^{15}$.

O BNH foi extinto em 1986 no então governo Sarney, em uma época de reabertura política e grande crise econômica. Suas atribuições foram pulverizadas em diversos órgãos governamentais, tendo a Caixa Econômica Federal (CEF) assumido a maior responsabilidade sobre financiamento habitacional no país. Todavia, seu grande legado de trabalhar moradia enquanto mercado ainda permanece arraigado na realidade habitacional brasileira, enquanto as bolhas especulativas do setor da construção civil e do setor imobiliário fornecem grandes obstáculos à efetivação do direito fundamental social à moradia no país. Não obstante, a política do BNH estimulou a associação entre direito à moradia e direito à propriedade, pois se pautava pela diretriz de "acesso à casa própria”, reduzindo a questão da moradia digna e da cidadania aos que podiam ser "proprietários", contribuindo para formar o ideário do "sonho da casa própria", tão difundido em nossa cultura. Encontrava-se implícita ainda a ideia de que a casa própria poderia desempenhar um papel ideológico importante, transformando o trabalhador de contestador em "aliado da ordem"16, sendo assim mais uma manobra de controle das camadas populares do que propriamente uma política de acesso ao direito fundamental à moradia.

\section{GENTRIFICAÇÃO E MORADIA: DE DIREITO FUNDAMENTAL SOCIAL A ATIVO FINANCEIRO}

A expressão "gentrificação" é tida como um conceito fundamental para o estudo das transformações experimentadas pelas cidades no mundo contemporâneo, sendo amplamente utilizada por pensadores das mais diversas áreas do conhecimento

\footnotetext{
${ }^{15}$ MARICATO, Ermínia. Habitação e Cidade. São Paulo: Atual, 1997. P. 46

${ }^{16}$ ANDRADE, Luís Aureliano Gama de. Política urbana no Brasil: o paradigma da organização e a política. Estudos Cebrap, São Paulo, n. 18, p. 117-47, out./dez. 1976.
} 
para explicar os influxos da vida urbana em nossos tempos. A palavra deriva do substantivo inglês "gentry," referindo-se a indivíduos ou grupos "origem nobre", "bem nascidos", designando um processo de elitização de determinados espaços da cidade anteriormente caracterizados como áreas predominantemente populares.

O geógrafo Neil Smith, professor catedrático de geografia e antropologia de Nova York, foi o responsável por empregar a expressão "gentrification" sob uma perspectiva crítica, aplicando-a no contexto das relações entre a valorização imobiliária e a expulsão dos moradores originais nas experiências de renovação de áreas centrais. Esse fenômeno passou a ocorrer com frequência no fim dos anos 1970, em várias cidades do mundo, no âmbito dos processos de globalização e de transformação da gestão das cidades na era neoliberal, sendo os estudos do professor Neil Smith foram essenciais para compreendê-lo. ${ }^{17}$

Smith diferencia três tipos básicos de gentrificação: a) promotores de moradia que compram uma determinada propriedade, reabilitam-na e a revendem com intenção de lucrar; b) particulares que compram uma propriedade e a reabilitam para nela viver; c) proprietários que reabilitam as moradias que possuem com a finalidade de alugá$\operatorname{las}^{18}$. O autor analisa o processo que se instaura nos bairros, observando seus períodos de crescimento, declínio e revitalização ou renovação potenciais, analisando os ciclos e as disputas econômicas que ocorrem entre os grupos sociais com a sequente mudança da paisagem, do custo de vida e serviços ${ }^{19}$. Chama atenção a forma como, dos anos 80 em diante, esse processo passou a ser identificado de forma maciça ao redor do mundo, sendo hoje um fenômeno bastante comum nas mais diversas cidades tanto dos países desenvolvidos como em desenvolvimento. É comum utilizar-se do termo "revitalização" de determinadas áreas urbanas para velar um verdadeiro processo de "higienização", "limpeza social".

Em oposição à prática do planejamento urbano, surge a corrente pósmodernista da arquitetura e passa-se à execução de projetos urbanos fragmentados, perdendo força a visão do espaço como algo a ser construído com propósitos sociais, pensando as intervenções nos espaços urbanos de forma mais parcial ou pontual, de

\footnotetext{
${ }^{17}$ SMITH, Neil. Gentrificação, a fronteira e a reestruturação do espaço urbano. Tradução: Daniel de Mello Sanfelici. GEOUSP - Es paço e Tempo, São Paulo, n. 21, pp. 15 - 31, 2007. Disponível em: http://citrus .uspnet.usp.br/geousp/ojs -2.2.4/index.php/geous p/article/view/268/ 140.

18 BATALLER, Maria Alba Sargatal. O estudo da gentrificação. Revista Bibliográfica de Geografía y Ciencias Sociales (ISSN 1138-9796), Universidad de Barcelona - $\mathrm{n}^{\circ}$ 228, 3 de mayo de 2000, com o título El estudio de la gentrificación. Tradução de Maurilio Lima Botelho (UFRRJ).

19 SMITH, Neil. Toward a theory of gentrification: a back to the city movement by capital not people, Journal of the American Planning Association, 45, pp. 538-548.
} 
forma "independente e autônoma a ser moldada segundo objetivos e princípios estéticos que não têm necessariamente nenhuma relação com algum objetivo social abrangente $(\ldots)^{, 20}$. Esse processo é concomitante à emergência do neoliberalismo como modelo econômico, provocando mudanças em muitas cidades que, diante de inúmeros fatores como a desindustrialização, o enxugamento da produção e precarização do trabalho, a perda da capacidade de investimentos do setor público e o aumento do setor de serviços, financeiro, de consumo e de entretenimento, vêm induzindo a certa mudança de visão nas práticas tradicionais, não só do Estado, mas de outros agentes interventores sobre o espaço urbano $^{21}$.

Nesse contexto, com o surgimento de projetos coadunados com essa nova ideologia emergente, as "renovações" e "revitalizações" (e outros substantivos com o prefixo "re") operadas no espaço urbano passaram a contemplar as camadas mais poderosas da sociedade e o grande poderio do mercado imobiliário, instalando um processo de elitização principalmente das áreas centrais, nas quais a oferta de serviços públicos e privados é de fácil acesso, bem como a maior facilidade de locomoção e mobilidade urbana, entre outras vantagens. Decorreu desse processo que, sobretudo nas grandes metrópoles, diversas áreas foram revitalizadas para que fossem utilizadas por grupos sociais de alta renda, gerando conflitos e expulsão dos moradores e usuários originais daquelas localidades, bem como o apagamento da história daquelas regiões urbanas, muitas vezes tradicionais e compostas por edifícios antigos, detendo valor histórico e cultural.

Desta feita, o processo de gentrificação se mostra bastante interessante para os setores de investimento imobiliário, uma vez que as áreas gentrificadas tornam-se altamente valorizadas seja pelo valor do terreno, do imóvel ou do aluguel. Neste último caso, em se tratando de relação de inquilinato, verifica-se que a alta dos preços gera "expulsão" de moradores devido aos preços dos aluguéis mais altos, ou mesmo pela em razão da venda e demolição do imóvel alugado. Vejamos o exemplo da cidade de São Paulo:

No caso de São Paulo, dos anos 1990 à atualidade, percebe-se um centro em vias de gentrificação, com uma série de elementos e pressupostos já consolidados, entre os quais: a) uma legislação urbana propícia aos especuladores imobiliários; b) investimentos do Governo

\footnotetext{
${ }^{20}$ HARVEY, David. Condição pós-moderna. São Paulo, Edições Loyola.1992, p. 69.

21 SANTOS, André da Rocha. Revitalização para quem? Política urbana e gentrificação no Centro de Santos. Cad. Metrop., São Paulo, v. 16, n. 32, pp. 587-607, nov 2014. Disponível em: http://www.cadernos metropole.net/component/content/article/31/50-306.
} 
do Estado e da Prefeitura em instituições e eventos culturais; c) o aumento dos conflitos, da vigilância policial e da criação de discursos higienizantes; d) a criação de uma "cidade revanchista" que, como indicado por Neil Smith (1996), reprime as minorias opositoras à gentrificação - como os moradores de rua, os químico-dependentes e os movimentos populares por moradia; e) bem como o engajamento de entidades civis e representantes das classes sociais prejudicadas, na resistência ante a transformação e re-significação dos espaços em questão ${ }^{22}$.

O que se observa de maneira geral é que, quando se trata do fenômeno da gentrificação, há um "triunfo" dos interesses privados no espaço urbano, prevalecendo aqueles que possuem condições econômicas de desfrutar das garantias que o Estado deveria prover, como lazer e segurança, passando os direitos fundamentais a se tornarem ativos financeiros, mercadorias que podem ser arcadas pelos que são dotados de capacidade econômica. Todo o arcabouço valorativo que permeia as normas jurídicas sobre a política urbana é fragilizado quando os mecanismos de controle do espaço urbano se submetem de forma passiva aos interesses de mercado. É o que veremos a seguir a respeito da política do aluguel.

\section{POLÍTICAS DE ALUGUEL COMO ALTERNATIVAS HABITACIONAIS}

\subsection{A política pública do aluguel social}

Conforme já apontado, as políticas públicas habitacionais no Brasil arraigaram uma cultura que relaciona fortemente o direito à moradia com o direito à propriedade, sendo o "sonho da casa própria" um ideal bastante difundido e fomentado no país. No entanto, a necessidade dos cidadãos consiste em morar, e não possuir bem imóvel. Em que pese o foco voltado para aquisição de propriedade, o aluguel é uma realidade expressiva no cotidiano dos brasileiros, porém o instituto do inquilinato não é eixo prioritário nas políticas públicas de moradia, sendo também a legislação brasileira um modelo não intervencionista, em que os contratos e os preços têm eminentemente a presença da autonomia privada:

A política habitacional no Brasil nunca privilegiou a locação como uma possibilidade. Apesar de ser um dos componentes básicos da atual políica, optou-se pela propriedade da casa, e isso contribuiu para que as nossas cidades se esparramassem pela periferia, tornando-se entes ingovernáveis. $\mathrm{O}$ desejo da casa própria se tornou uma meta a

\footnotetext{
${ }^{22}$ UCHÔA, Fabio Raddi. Espaços e Imagens da Gentrificação no Centro de São Paulo. Revista Novos

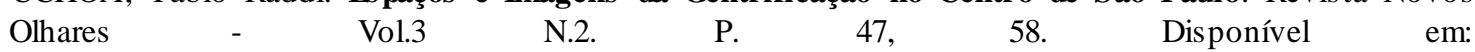
http://www.revis tas.usp.br/novos olhares/article/viewFile/90202/92910.
} 
ser conquistada por todos. Esse discurso hegemônico prevaleceu e ainda prevalece nos programas de habitação. Na verdade, a locação nunca foi entendida pelos governos, técnicos e os movimentos como solução para o déficit habitacional ${ }^{23}$.

Ocorre que, com os processos de gentrificação e a valorização dos terrenos e imóveis, e num contexto em que os direitos se tornam mercadorias, o acesso ao direito à moradia tem sido cada vez mais oneroso. Este fenômeno afeta não apenas as relações de compra e venda, mas todas as demais relações imobiliárias, como a alta do preços dos aluguéis, que, conforme o apontado pela pesquisa da Fundação João Pinheiro, tem representado uma despesa excessivo do orçamento das famílias de baixa renda, que comprometem $30 \%$ de seus rendimentos com pagamento de aluguel. Trata-se de um dado bastante relevante, apontando para uma possível alternativa estatal de auxílio às familias pobres, que precisam habitar e não necessariamente de propriedade.

Estas famílias, sobretudo, encontram-se à margem da valorização imobiliária e seus preços, que variam segundo as leis de mercado, sofrendo o impacto negativo advindos das obras de valorização e revitalização realizadas pela iniciativa pública e privada. Estas questões apontam para a temática do aluguel social, que tem se apresentado uma alternativa viável para a questão do déficit habitacional. É o que observa Luiz Kohara, Francisco Comaru e Carolina Ferro, que fornecem diversos argumentos em favor da medida:

locação social constitui-se em uma das formas de manter a moradia fora do mercado e protegida do mesmo, assim como de assegurar o investimento $\mathrm{p}$ blico para o interesse social no longo prazo. ma vez que a moradia é p blica e não poderá ser vendida, o investimento de recursos $\mathrm{p}$ blicos na produção da moradia torna-se um investimento de caráter mais permanente, protegido das turbul ncias do mercado imobiliário que, em regiões sujeitas a grande valorizaçãoimobiliária, pode pressionar a população de baixa renda a vender ou repassar suas casas e se mudar para regiões mais baratas da cidade - processo conhecido como expulsão branca $^{24}$.

Segundo estudo do Banco Interamericano de Desenvolvimento (BID), o aluguel social poderia ajudar a reduzir o déficit habitacional no Brasil ${ }^{25}$. Além disso, a

\footnotetext{
${ }^{23}$ BALTRUSIS, Nelson; MOURAD Laila Nazem Política habitacional, regulação do solo e aluguel s ocial no Brasil. Cad. CRH vol.27 n.71 Salvador June/Aug. 2014. Disponível em: http://dx.doi.org/10.1590/S0103-49792014000200001.

24 COMARU, Francisco; FERRO, Carolina; KOHARA, Luiz. Pela retomada dos programas de locação social. Dis ponível em: https://observasp.wordpres s.com/2015/04/22/pela -retomada-dos programas -de-locacao-s ocial/. Aces so em 20/03/2016.

25 BLANCO, Andrés G.; CIBILS, Vicente Fretes; MUÑOZ, Andrés F. Procura-s e casa para alugar

Opções de política para a América Latina e Caribe. Banco Interamericano de Desenvolvimento.
} 
promoção da Locação Subsidiada de Unidades Habitacionais em Centros Históricos e Áreas Urbanas Consolidadas é prevista no próprio Plano Nacional de Habitação de 2009 (PlanHab), enquanto uma de suas linhas programáticas. De acordo com o plano, esta modalidade:

Visa constituir-se numa alternativa de acesso à moradia que permite mobilidade espacial dos beneficiários que necessitam mudar os locais de residência ou que, por sua condição de vulnerabilidade social, não podem se responsabilizar pela propriedade de um imóvel ${ }^{26}$.

A locação subsidiada, se realizada como prevista no PlanHab, em Centros Históricos e em Áreas Urbanas Consolidadas, pode se efetivar enquanto um eficaz instrumento de salvaguardar a realização da moradia adequada como orientada pelo Comentário Geral no 04 , supra citado, do Comitê de Direitos Econômicos, Sociais e Culturais da Organização das Nações Unidas, uma vez que com a outorga de legitimidade do Estado, subsidiando a locação com a infraestrutura adequada e contra a ordem geográfica excludente dos nossos subúrbios, a moradia obedecerá aos requisitos de segurança da posse; disponibilidade de serviços, materiais, instalações e infraestrutura; economicidade; habitabilidade; acessibilidade; localização e adequação cultural. Além disso, essa medida poderia garantir a função social da propriedade a muitos imóveis que hoje servem apenas à acumulação de valor da especulação imobiliária.

Ocorre que, não somente no Brasil como também nos demais países da América Latina, as políticas públicas de habitação tem priorizado a concessão da propriedade de um bem imóvel às familias de baixa renda. No mesmo estudo promovido pelo Banco Interamericano de Desenvolvimento (BID), foram analisadas 19 áreas metropolitanas, dentre elas as das cidades de Curitiba, Salvador e São Paulo, com intuito de mapear as potencialidades de aluguel social como instrumento para diminuir o déficit de moradias naquelas metrópoles. A pesquisa demonstrou que o aluguel subsidiado, majoritariamente utilizado em situações emergenciais ou transitórias, poderia servir como instrumento hábil à promoção de moradias dignas para as familias de baixa renda.

Nova Ioque, 2014. Disponível em: http://www.iadb.org/pt/noticias /comunicados -de-imprens a/2014-0527/deficit-habitacional-no-bras il-e-aluguel-s ocial,10825.ht ml. Aces so em 20/03/2016.

26 BRASIL. Plano Nacional de Habitação. Ministério das Cidades / Secretaria Geral de Habitação. Brasíla, 2010. P. 155. 
O estudo recomenda ainda que a política habitacional não deve se limitar à produção de unidades para a venda, devendo oferecer alternativas aos segmentos da população que não podem ou não querem ser proprietários de imóveis. O próprio BID aponta, contudo, que entre as principais barreiras para este tipo de política estão a cultura da posse do imóvel em detrimento ao aluguel, bem como as dificuldades de gestão dos imóveis por parte do poder público, como as despesas com condomínio, IPTU e taxas, o que abriria possibilidades, por exemplo, para a realização de parcerias público-privadas.

No caso da cidade de São Paulo, a partir do ano de 2001, durante a gestão de Marta Suplicy, o executivo municipal tomou a iniciativa de produzir habitação de interesse social no centro da cidade utilizando o aluguel social como alternativa. Assim, o município se mantinha na condição de proprietário dos imóveis, alugando-os a um baixo custo para famílias de baixa renda, dando início ao Programa de Locação Social como forma de inclusão habitacional à população de baixa renda na região central. A experiência paulistana foi pioneira no país e é a única a ter viabilizado empreendimentos para esta finalidade específica. Em que pese a abordagem limitada do direito à moradia como sinônimo de "teto", o Programa foi interessante fato de a locação social se dar nas áreas centrais da cidade, onde há maior oferta de serviços públicos e privados, maior faciliade de locomoção e maior acesso à cultura e lazer.

Para além de uma política emergencial, outros países do mundo empregam de forma sistemática a locação social como política pública de direito à moradia ${ }^{27}$. Podemos citar como exemplo a França que apresenta um número expressivo de moradia de aluguel social com um total de 149.300 moradias em $2012^{28}$ :

Parc locatif social au $1^{\mathrm{er}}$ janvier 2012

\begin{tabular}{|l|c|c|c|c|c|}
\hline & $\begin{array}{c}\text { Parc locatif social au } \\
\text { 01/01/2012 }\end{array}$ & $\begin{array}{c}\text { Part } \\
(\%)\end{array}$ & $\begin{array}{c}\text { Évolution } \\
2012 / 2011(\%)\end{array}$ & \multicolumn{2}{|c|}{ Loge ments sociaux } \\
\cline { 4 - 5 } & & & & $\begin{array}{c}\text { pour 100 résidences } \\
\text { principales }\end{array}$ & $\begin{array}{c}\text { pour } \\
\text { 1 000 habitants }\end{array}$ \\
& & & & &
\end{tabular}

Sources : SOeS, RPLS 2012 - DGI, TH 2010 - Insee, Estimations de population au $1^{\text {er }}$ janvier 2010

\begin{tabular}{lr|r|r|r|r|}
\hline Dordogne 13378 & 9,0 & 2,9 & 7,3 & 32,3 \\
\end{tabular}

\footnotetext{
${ }^{27}$ A França dispõe nas grandes cidades em média $20 \%$ de residências para aluguel social. Dados de: GRAËFFLY, Romain. Le logement social. Étude comparée de l'intervention publique en France et en Europe occidentale. Paris: LGDJ, 2005. P. 180, Dispõe ainda desse sistema: Portugal, Dinamarca, Finlândia, Islândia, Noruega, Suécia. Idem, p. 156-157.

${ }^{28}$ Dados disponíveis no link: http://www.ins ee.fr/fr/themes /document.as p?reg_id=4\&ref_id=19882 . Acesso em: 03/04/2016.
} 


\begin{tabular}{|c|c|c|c|c|c|}
\hline & Parc locatif social au & Part & Évolution & \multicolumn{2}{|c|}{ Loge ments sociaux } \\
\hline & 01/01/2012 & $(\%)$ & 2012/2011 (\%) & & \\
\hline \multicolumn{4}{|c|}{ pour 100 résidences principales } & \multicolumn{2}{|r|}{$\begin{array}{c}\text { pour } \\
1000 \text { habitants }\end{array}$} \\
\hline Gironde & 84219 & 56,4 & 3,5 & 13,1 & 58,2 \\
\hline Landes & 11616 & 7,8 & 3,5 & 7,0 & 30,3 \\
\hline Lot-et-Garonne & 9780 & 6,6 & 2,1 & 6,8 & 29,5 \\
\hline $\begin{array}{l}\text { Pyrénées- } \\
\text { At lantiques }\end{array}$ & 30263 & 20,3 & 3,1 & 10,5 & 46,2 \\
\hline Aquitaine & 149256 & 100,0 & 3,3 & 10,5 & 46,2 \\
\hline France & 4652300 & & 1,7 & 17,0 & 72,0 \\
\hline
\end{tabular}

Essas políticas apresentam contornos variados e guardam distinções em suas formas de aplicação dentro de cada país, podendo abarcar parques imobiliários destinados à locação social, ou ainda o sistema de subsídios para acesso ao mercado convencional de aluguel. $\mathrm{Na}$ União Europeia, os programas de aluguel social chegam a atender um quinto das famílias, enquanto o percentual de imóveis ocupados pelo próprio proprietário representa pouco mais da metade do estoque total, atingindo $56 \%{ }^{29}$. O estudo de Mariana Werneck e Orlando Santos Junior aponta que, na Europa, a política de habitação social prioriza sinteticamente as seguintes diretrizes: a crescente elaboração de regulações que estabeleçam normas mínimas de habitabilidade; a imposição de limites aos alugueis do setor privado; a concessão de alugueis de habitação social (com exceção dos países do Mediterrâneo e Bélgica $^{30}$ ); e a oferta de subsídios individuais, a partir da adoção de políticas de linha neoliberal.

\subsection{Gentrificação e controle dos preços do aluguel}

29 WERNECK, Mariana; SANTOS JUNIOR Orlando. Plano de habitação de Interesse Social: desafios e perspectivas para um programa locação social. Disponível em: http://www.obs ervatoriodas metropoles .net/index.php?option=com_k2\&view=item\&id=1264:phis des afios-e-pers pectivas -para-um-programa-de-loca\% $\% 3 \% \mathrm{~A} 7 \% \mathrm{C} 3 \% \mathrm{~A} 30-$ social\&Itemid=180\&t mp l=co mponent $\&$ print $=1 \&$ lang=pt. Acesso em: 15/03/2016.

${ }^{30} \mathrm{Na}$ Bélgica a Corte Constitucional reconheceu o direito dos locatários das moradias sociais na decisão C.A., arrêt $n^{\circ}$ 33/2007. Sobre o tema VAN AKEN, Nicolas, Droit au logement et droit de propriété: Convergences et divergences, pp 89-94. 
A partir do mês de junho do ano de 2015, a capital alemã Berlim passou a adotar uma legislação para impedir que os preços dos alugueis tenham alta maior que $10 \%$ da média da região, estendendo o teto de reajustes para novos contratos. A medida foi tomada com o intuito de evitar o que se observa de forma expressiva nas diversas capitais europeias, como as cidades de Paris e Londres, nas quais a gentrificação afetou os moradores tradicionais e de baixa renda que habitavam as áreas centrais, que, devido à alta disparada dos preços dos aluguéis, tiveram que migrar para bairros periféricos. A gentrificação em Berlim já vinha sendo observada a partir dos grandes fluxos de migração para as áreas periféricas e alta da valorização imobiliária, prejudicando também os estabelecimentos comerciais, e por consequência, o turismo daquela cidade. Esse processo fez com que a lei de controle dos aluguéis, bandeira defendida pelos ativistas da cidade contra a gentrificação, levassem o parlamento da capital alemã a aprovar uma lei específica para a regulação do preço dos aluguéis. Consequência disso é que, em bairros muito gentrificados como os turísticos Kreuzberg, Neukölln e Friedrichshain, os aluguéis não podem subir mais que $10 \%$ da média da região, colocando um "freio" nas leis de mercado e a alta descontrolada dos preços imobiliários ${ }^{31}$.

Em agosto de 2015 foi a vez da capital francesa, Paris, inovar seu ordenamento jurídico com a aprovação de uma lei que limita o preço dos aluguéis. Assim como em Berlim, esta era uma reivindicação antiga dos moradores e dos movimentos sociais diante dos elevados valores cobrados pelos proprietários de imóveis a título de aluguel, que teve um aumento expressivo nos últimos 10 anos, em grande parte devido à conversão dos apartamentos residenciais em imóveis para turistas. A lei francesa dividiu a cidade de Paris em 14 regiões, estabelecendo diferentes faixas de preço, definidas em euros por metros quadrados, com valores máximos estabelecidos que vão de $€ 27$ por metro quadrado até $€ 37$, como nas proximidades do Museu do Louvre e das ithas do Rio Sena ${ }^{32}$.

Além da Alemanha e da França, dispositivos que limitam o valor dos aluguéis também existem na Holanda, Suíça e Suécia, sendo este último o país que realiza a mais estrita regulação do mercado, onde os reajustes dos preços não podem ultrapassar $5 \%$ do valor estabelecido pelos municípios. No Brasil, contudo, ainda não existe uma lei

\footnotetext{
${ }^{31}$ Dados disponíveis no endereço eletrônico: http://www.citylab.com/hous ing/2015/11/berlin -justshowed-the-world-how-to-keep-hous ing-affordable/415662/.

32 Informações disponíveis nos endereços eletrônicos: http://www.france24.com/en/20150801-rentcontrol-law-paris -france-effect-regulations ; https://www.referidf.com/.
} 
específica aprovada que trate do assunto, em que pese a forte atuação dos movimentos sociais, principalmente nas capitais São Paulo e Rio de Janeiro, com destaque para o Movimento dos Trabalhadores Sem-Teto (MTST), que tem como uma de suas bandeiras a regulação do preço do aluguel e o combate ao lucro desenfreado do mercado imobiliário em detrimento do bem estar da população mais pobre.

\section{CONCLUSÃO}

É necessário buscar arranjos diferenciados e alternativas que indiquem novos horizontes para as políticas públicas habitacionais. Ao estruturar programas de aluguel social e subsidiado, além de desvincular a relação entre moradia e propriedade, é possível intervir no mercado de preços de aluguel, evitando que a população de baixa renda seja expulsa pela valorização imobiliária, a elitização e a segregação urbana. Portanto, essas medidas têm sido entendidas, a exemplo de diversas cidades europeias, como possibilidades concretas para a promoção de cidades mais justas, inclusivas e democráticas.

Em síntese, o estudo procurou demonstrar: a importância das políticas de aluguel na provisão do direito à moradia e como forma de ajuste às injustiças promovidas pelas leis de mercado; o combate à visão que necessariamente entrelaça moradia e propriedade; a importância da intervenção pública no que tange aos efeitos da gentrificação e às "expulsões brancas" promovidas pelas revitalizações e demais empreendimentos públicos e privados de valorização imobiliária, sobretudo o controle do preço dos aluguéis, a exemplo das cidades mencionadas no artigo.

\section{REFERÊNCIAS BIBLIOGRÁFICAS}

ANDRADE, Luís Aureliano Gama de. Política urbana no Brasil: o paradigma da organização e a política. Estudos Cebrap, São Paulo, n. 18, p. 117-47, out./dez. 1976.

BALTRUSIS, Nelson; MOURAD, Laila Nazem. Política habitacional, regulação do solo e aluguel social no Brasil. Cad. CRH, vol.27, n.71. Salvador. June/Aug. 2014. Disponível em: http:/dx.doi.org/10.1590/S0103-49792014000200001. Acesso em: 15/03/2016.

BATALLER, Maria Alba Sargatal. O estudo da gentrificação. Revista Bibliográfica de Geografía y Ciencias Sociales, Universidad de Barcelona - $\mathrm{n}^{\circ}$ 228, 3 de mayo de 2000, com o título El estudio de la gentrificación. Tradução de Maurilio Lima Botelho (UFRRJ). 
BLANCO, Andrés G.; CIBILS, Vicente Fretes; MUÑOZ, Andrés F. Procura-se casa para alugar Opções de política para a América Latina e Caribe. Banco Interamericano de Desenvolvimento. Nova Ioque, 2014. Disponível em: https:/publications.iadb.org/bits tream/handle/11319/6426/FMM\%20MG\%20Procurase $\% 20$ casa\%20para\%20alugar.pdf?sequence $=3$. Acesso em: 15/03/2016.

BRASIL. Plano Nacional de Habitação. Ministério das Cidades / Secretaria Geral de Habitação. Brasîla, 2010. P. 155.

BRASIL, Secretaria de Direitos Humanos da Presidência da República. Direito à Moradia Adequada. Brasília: Secretaria Nacional de Direitos Humanos, 2013. P. 13.

CARLOS, Ana Fani Alessandri. A Tragédia Urbana. In. CARLOS, Ana Fani Alessandri; VOLOCHKO, Danilo; ALVAREZ, Isabel Pinto (orgs.). A Cidade Como Negócio. São Paulo: Contexto, 2015. p. 50.

CASTELLS, Manuel. A intervenção administrativa nos grandes centros urbanos. Espaço e Debates. São Paulo, n. 6.1982.

COMARU, Francisco; FERRO, Carolina; KOHARA, Luiz. Pela retomada dos programas de locação social. Disponível em:

https://observasp. wordpress.com/2015/04/22/pela-retomada-dos-programas-de-locacaosocial. Acesso em: 15/03/2016.

FUNDAÇÃO JOÃO PINHEIRO. Déficit Habitacional no Brasil / 2011-2012. Governo de Minas Gerais, Belo Horizonte, 2015. Disponível em: http://www.fjp.mg. gov.br/index.php/docman/cei/559-defic it- habitacional-20112012/file. Acesso em: 15/03/2016.

GRAËFFLY, Romain. Le logement social. Étude comparée de l'intervention publique en France et en Europe occidentale. Paris: LGDJ, 2005

HARVEY, David. Condição pós-moderna. São Paulo, Edições Loyola,1992.

INSTITUTO BRASILEIRO DE PESQUISA E ESTATÍSTICA (IBGE). Censo Demográfico 2000. Disponível em:

http://www.ibge.gov.br/home/estatistica/populacao/censo2000/populacao/censo2000_p opulacao.pdf.

LUNARDI, Soraya Regina Gasparetto. Finalidades e Formas de efetivação do Direito Fundamental à Habitação: a inclusão social com base na expe riência constitucional francesa. In. LUNARDI, Soraya Regina Gasparetto (Org). Inclusão Social e sua Efetivação. Curitiba: CRV, 2011.

MARICATO, Ermínia. Habitação e Cidade. São Paulo: Atual, 1997. P. 46

MEDEIROS, Sara Raquel Fernandes de. BNH: outras perspectivas. Disponível em: http://www.cchla.ufrn.br/cnpp/pgs/anais/Artigos\%20REVIS ADOS/BNH,\%20outra\%20 pespectiva.pdf. Acesso 21.02.2016. 
RODRIGUES, Arlete Moysés. Moradia nas Cidades Brasileiras. 2 ed. São Paulo: Contexto, 1989.

SANTOS, André da Rocha. Revitalização para quem? Política urbana e gentrificação no Centro de Santos. Cad. Metrop., São Paulo, v. 16, n. 32, pp. 587-607, nov 2014. Disponível em:

http://www.cadernosmetropole.net/component/content/article/31/50-306. Acesso em: $15 / 03 / 2016$.

SANTOS JUNIOR, Orlando; Mariana WERNECK. Plano de habitação de Interesse Social: desafios e perspectivas para um programa locação social. Disponível em: http://www.observatoriodas metropoles.net/index.php?option=com_k2\&view=item\&id= 1264:phis-desafios-e-perspectivas-para-um-programa-de-loca\%C3\%A7\%C3\%A3osocial\&Itemid=180\&lang=pt. Acesso em: 15/03/2016.

SMITH, Neil. Toward a theory of gentrification: a back to the city movement by capital not people. In: Journal of the American Planning Association, 1979, vol. 45, p. 538-548.

Gentrificação, a fronteira e a reestruturação do espaço urbano. Tradução: Daniel de Mello Sanfelici. GEOUSP - Espaço e Tempo, São Paulo, n. 21, pp. 15 - 31, 2007. Disponível em: http://citrus.uspnet.usp.br/geousp/ojs-

2.2.4/index.php/geousp/article/view/268/140.

UCHÔA, Fabio Raddi. Espaços e Imagens da Gentrificação no Centro de São Paulo. Revista Novos Olhares - Vol.3 N.2. P.47, 58. Disponível em: http://www.revistas. usp.br/novosolhares/article/viewFile/90202/92910. Acesso em: $15 / 03 / 2016$.

VAN AKEN, Nicolas, Droit ao logement et droit de propriété: convergences et divergences. In: LAMBERT, Pierre, PUÉCHAVI, Michel; PLAS, Daniel (orgs.). Le droit au logement: vers la reconnaissance dee droit fundamental de $\mathrm{l}^{\text {re }}$ tre humain. Bruxelles, Bruylant, 2008. 